\title{
Zero Emission Mobility Campus, Using a German Example - Theory to Support a Sustainable Decision- Making by Suggestion
}

\author{
By Rebecca Heckmann ${ }^{*}$, Alexandra Mittelstädt ${ }^{\dagger}$, Lutz Gaspers ${ }^{\dagger}$ \& \\ Jörn Schönberger
}

\begin{abstract}
Mobility is a basic human need that needs to be satisfied. However, this need for mobility goes hand in hand with transport, which has negative impacts on people, the environment and the climate. Transport causes different emissions with specific consequences. But not every means of transport causes the same number of emissions. In this way, harmful emissions can be reduced by specifically influencing behaviour. This is done by making suggestions when choosing the means of transport. Suggestion promotes the sustainability aspect in decision-making for or against a means of transport. By strengthening the sustainability aspect, the decision in favour of a sustainable mode of transport should be strengthened. A decision is then no longer based on the priority factors of time, costs, convenience and flexibility, but also on environmental compatibility. In this case, a decision is more likely to be made in favour of a more environmentally friendly mode of transport, as awareness of the consequences of one's own transport behaviour is created. This will reduce transport emissions and help to protect the climate, the environment and people. For precisely this suggestion, a model is going to be developed that shows potential approaches and identifies indicators that describe the potential influence on behaviour. Based on the developed model, a suitable suggestion instrument can be developed which is subject to theoretical principles of consumer behaviour, psychological decision making and the transport choice process.
\end{abstract}

Keywords: Behavioural Influence in Mobility, Choice of Mode of Transport, Decision Behaviour in Traffic, Mobility Behaviour of Students, Sustainable Mobility.

\section{Introduction}

Mobility and Choice of Mode of Transport

Mobility is a basic need of mankind. It makes it possible to perceive changes in location between different activities, such as working and living. This is based on developments in urban structures. The separation of functions associated with the Athens Charter, i.e. the local separation of activities, implied necessary changes of location between these.

\footnotetext{
"Researcher, University of Applied Sciences Stuttgart, Germany.

'Researcher, University of Applied Sciences Stuttgart, Germany.

${ }^{\ddagger}$ Professor, University of Applied Sciences Stuttgart, Germany.

•Professor, Technical University Dresden, Germany.
} 
These changes of location often take place with motorized individual traffic (Institute for Social Science, 2017). This frequency of motorized individual transport leads to effects of an ecological, urban-structural, social and economic nature.

One of the acute impacts that global mankind is dealing with in the $21 \mathrm{st}$ century is climate change, which has to be differentiated into natural and anthropogenic greenhouse gas emissions that favour climate change. Anthropogenic greenhouse gas emissions lead to an increased in total greenhouse gas emissions. "The surge in human greenhouse gas emissions and the observed temperature increase over the last 150 years has led to the conclusion that there is a direct causal link between greenhouse gas concentration and temperature development." (Hollerbach and Berner 2003).

Rudinger and his colleagues believe that this is mainly due to people's mobility behaviour, which in its opposite form is not compatible with environmental protection.

"It is increasingly evident that the corresponding (modern) lifestyles in affluent societies, and the mobility behaviours associated with such life styles, are not consistent with protection of environmental quality, efficient use of human, natural, and financial resources, and promotion of social cohesion and just distributions of opportunities and costs of using transport systems." (Rudinger et al. 2006).

The transport sector is responsible for $14 \%$ of global greenhouse gas emissions. Overall, $\mathrm{CO}_{2}$ emissions have risen sharply by over $90 \%$ since 1900 (IPCC 2014). Transportation is the only sector that has not achieved any significant $\mathrm{CO}_{2}$ reductions since 1990 (Federal Environment Agency, 2018). This can be traced back to the rising number of transport services (Institute for Social Science 2017). Although the specific fuel consumption of passenger cars between 1995 and 2016 led to lower fuel consumption due to improved overall efficiency and the use of more diesel vehicles with lower fuel consumption than a petrol car, the trend towards more efficient vehicles and the increasing use of higher consumption equipment contradicted these improvements (Federal Motor Transport Authority 2017).

Since transport performance is linked directly to economic performance, the traffic problem situation poses a challenge for society as a whole.

In order to achieve declining traffic emissions, it is necessary to separate transport performance from economic performance. Rising traffic volumes as a result of rising economic performance must be handled with lower emissions in order to limit increasing emission burdens and consequences such as climate change (Rhenish-Westphalian Institute for Economic Research 2010).

Environmental developments describe the need to reduce emissions in relation to passenger kilometres if transport performance in passenger kilometres is constant or increases.

This reduction in emissions is possible by influencing the choice or use of means of transport. Emissions per passenger-kilometre are reduced by switching to a lower-emission means of transport, a Federal Environment Agency means of 
transport or by increasing the occupancy rate of a passenger car in order to distribute emissions per kilometre among more people in the vehicle.

A compulsion to change choice or use is not easily possible and not desirable in our social system. Article 1 of the Basic Law describes human dignity, which in the opinion of the Federal Constitutional Court is based on freedom of decision (Federal Republic of Germany, 1949). In order to guarantee this freedom of decision also when deciding on a means of transport and its use, the question of voluntary possibilities to change behaviour arises.

The focus of this work is therefore the theory for the development of a suggestion instrument in the choice of means of transport on a voluntary basis. In order to approach this goal, a four-stage methodological approach was chosen, which is illustrated in Figure 1.

Figure 1. Approach

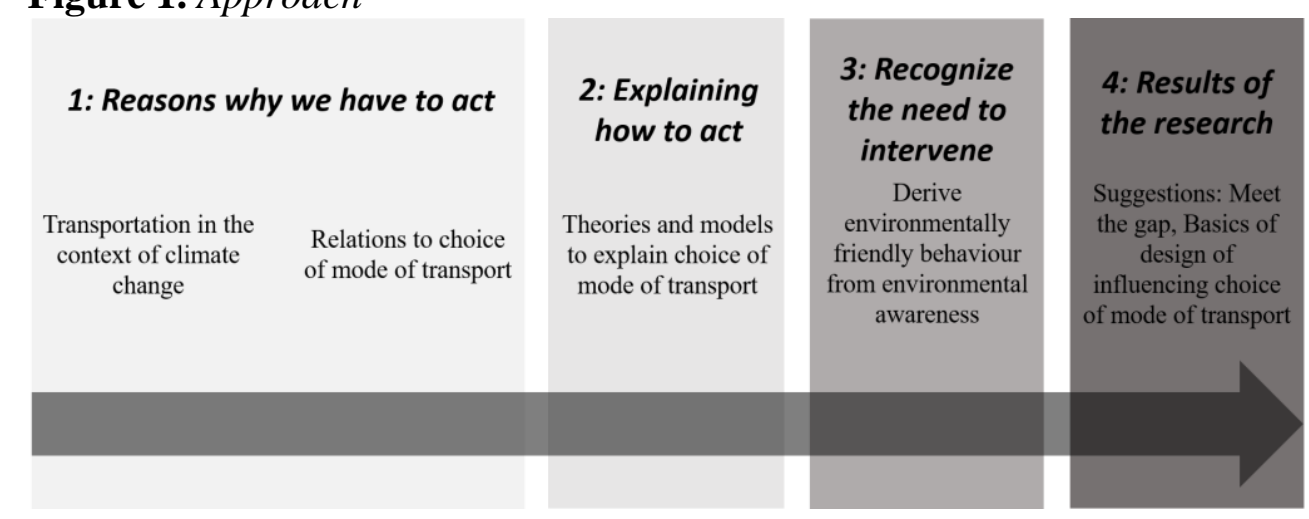

For the sake of clarity, the choice of means of transport in this paper also refers to carpooling or car sharing as an alternative means of transport, i.e. increasing the number of passengers while at the same time reducing the number of individual drivers.

The choice of mode of transport (making a decision) is a complex psychological process, which for example was presented by Pez in 1998 in his model of the choice of means of transport (Pez 1998). Accordingly, different internal and external characteristics influence the choice of means of transport. In the decision-making process, the properties of available means of transport are evaluated. Various factors influence this.

It is generally assumed that younger people are easier to influence than older ones. This for example is based on Busch-Geertsema (Busch-Geertsema 2018). According to her, there is a fixation on traffic behaviour and the development of a transportation routine in the phase between study and professional life. Both students and trainees are regarded as suitable target groups. Since the mobility behaviour among them has often not yet been determined, it is considered possible to influence them. For people in working life, the living conditions and patterns are generally fixed for the longer term and corresponding routines are anchored.

Based on this, research focuses on students and trainees in the first step. In later stages and when the first target groups have been successfully influenced, other groups can also be affected. 
First of all, it is important to have an overview of models and principles of decision-making and consumer behaviour as well as theory of choice of mode of transport.

Decisions and also the choice of mode of transport are based on same theoretical models. An important step in these models is the comparison of different factors influencing the decision.

In his model, Pez mentions speed, independence/flexibility, luggage transport and comfort as decisive factors. The representative survey of professors, students and employees of the Stuttgart University of Applied Sciences in 2018 shows that reliability, travel time, costs and flexibility are decisive factors in the choice of means of transport (Heckmann et al. 2019).

The results of Fürst and Oberhofer also verify this impression. In a survey of employees and students at German, Swiss and Austrian universities with a total of over 28,000 evaluated questionnaires, the attributes of the choice of means of transport according to their ranking were perceived as important: Reliability, availability, flexibility, value for money, cost, speed, safety, environmental friendliness and comfort (Fürst and Oberhofer 2012).

In Pez' model as well as in the survey of the Stuttgart University of Applied Sciences and the results of Fürst and Oberhofer it is noticeable that the aspect of environmental compatibility is subordinate.

To influence the choice of means of transport in terms of environmental compatibility is only possible through appropriate measures. Groß describes that the establishment of a change in mobility behaviour is a complex learning process that can only be achieved by forming opinions and changing attitudes and awareness (Groß 1998).

The aim of this work is to develop a medium that leads the user to an environmentally friendly alternative when choosing the means of transport. The focus is on the question of how the environmental aspect can be strengthened as a decision criterion so that users decide on the basis of environmental compatibility and thus choose an environmentally friendly option. At least subjectively and according to the decisive factors of reliability, travel time, costs and flexibility, the environmentally friendly means of transport are perceived as more disadvantageous than a car.

As the study at the Stuttgart University of Applied Sciences has shown, almost $100 \%$ of students uses sustainable means of transport (public transport, cycling or walking) (Heckmann et al. 2019). Due to lower fares of public transport for students, it is assumed that the decision for public transport is made by students due to their price sensitivity. Fuji and Gärling also support this view in 2003 and show that: "many have changed means of transport to university or work over the transition [between student and professional life]" (Fuji and Gärling 2003). From this it could be deduced that students use environmentally friendly means of transport during their studies, as these often have cost advantages, but this changes when price sensitivity decreases and cost advantages are possibly eliminated (for example, cheap public transport tickets for students).

In this context, the question arises as how environmental awareness can influence behaviour in order to avoid this upheaval between study and career. This 
can be considered sufficient for educational traffic in general. Studies show that pupils and similar groups are particularly frequent users of public transport. This leads to the point that in some places public transport can only be economical at all thanks to pupils. This is the case, for example, in rural areas (Deutsch 2013). Passengers who are undergoing training (apprenticeship or studies) are regarded as a group with homogeneous behaviour. For this group of people, who are in the phase before the transition between training and working life, there is presumably the potential to influence mobility behaviour and establish a mobility routine.

Figure 2. Process of Choice of Mode of Transport

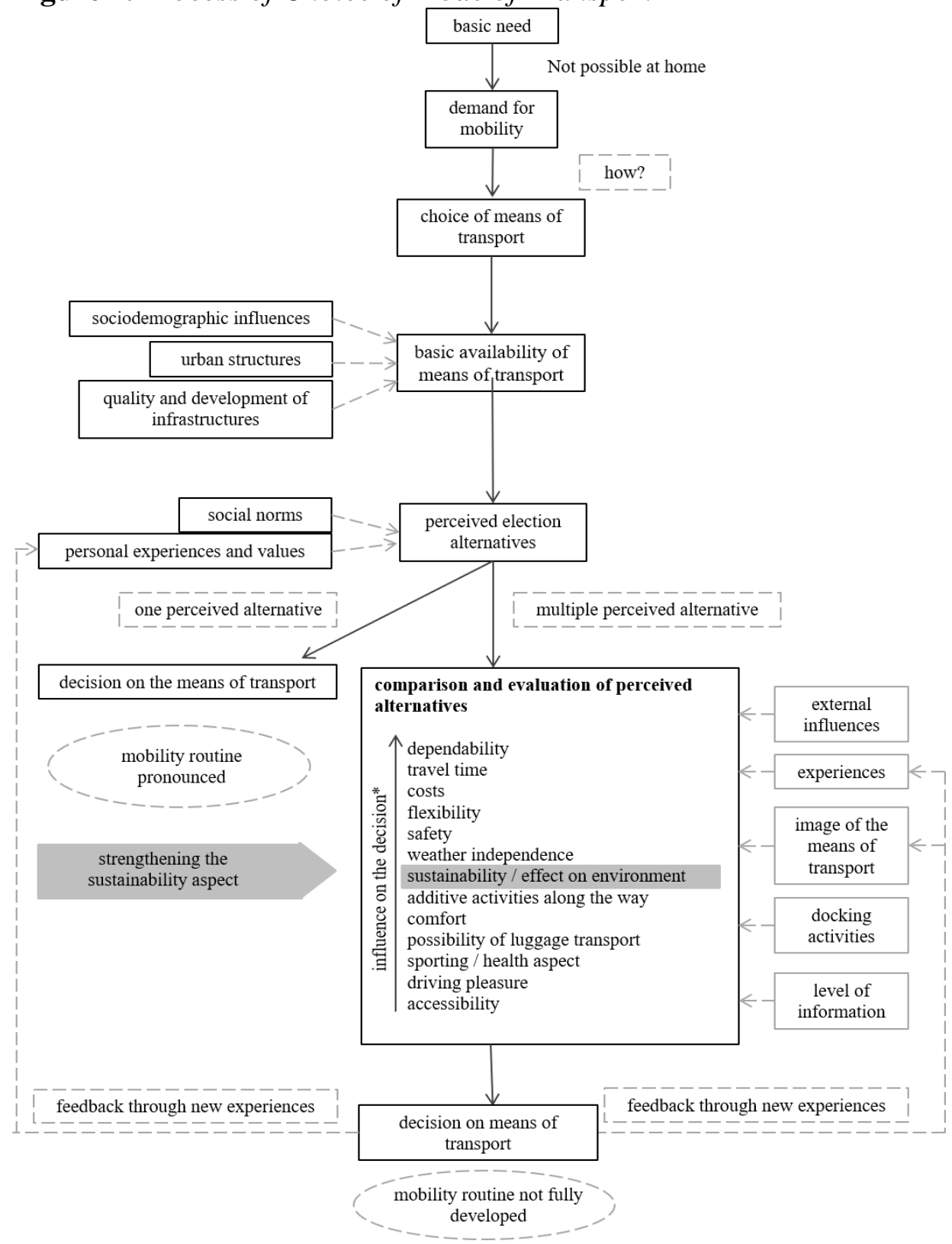

* Classification based on the HFTmobil study at the Stuttgart University of Applied Sciences on the question of how decisive the individual factors are for students.

Source: Pez 1998. 
Figure 2 shows the process of choosing a means of transport and the starting point for suggesting the environmental aspect. Suggestivity, and thus the potential for reducing traffic emissions, results exclusively from the perception of several alternative choices and the comparison process that results. This comparison process takes place subconsciously on the one hand, and partly consciously and actively on the other, for example by using route planners who compare different driving options with regard to some of the selection factors (mainly driving time, costs, flexibility, comfort).

Fugure 2 shows the suggestion in the phase of comparison and evaluation of the perceived choice alternatives (grey). The aim of the suggestion is to persuade the user to pay more attention to the environmental aspect in the assessment. This should lead to a decision in favour of more sustainable means of transport.

\section{Basics of Choice of Sustainable Mode of Transport}

Traffic-relevant decisions have different maturities. Only immediate, short-term decisions can be directly influenced by a suggestion instrument. Nevertheless, the feedback of a decision on experience and routine should also be able to influence medium- and long-term decisions as shown in Table 1 . Held differentiates between the following terms and types of choice (Held 1982):

Table 1. Classification of Transport-Relevant Decisions by Maturity

\begin{tabular}{|l|c|}
\hline Terms of choice & Type of choice \\
\hline Long-term & $\begin{array}{c}\text { Choice of workplace } \\
\text { Choice of apartment }\end{array}$ \\
\hline Medium-term & $\begin{array}{c}\text { Car ownership } \\
\text { Choice of means of transport for } \\
\text { commuting to work }\end{array}$ \\
\hline Short-term & $\begin{array}{c}\text { driving frequency } \\
\text { destination selection } \\
\text { Choice of means of transport (other) } \\
\text { Choice of time of day } \\
\text { route selection }\end{array}$ \\
\hline
\end{tabular}

A suggestion tool can influence short-term decisions, as it is assumed that for such decisions a comparison of different options will take place immediately before the action itself. This means that those short-term choices could be influenced. Relevant with regard to emissions are above all the choice of other means of transport, the frequency of travel and the choice of route: 
- Other means of transport: Leisure trips and those that do not take place regularly

- Frequency of travel: it is assumed that this can hardly be influenced, since it will probably be established how often the road user drives to a certain activity (example: a road user intends to make a short-term decision on how to get to an event). It is clear that he will drive back and forth to this activity.)

- Route choice: this can have an impact on emissions if different routes have different route lengths or different altitude profiles which affect consumption and therefore emissions.

The aim of the work is to develop a model that shows how decisions that Held believes can be influenced by a suitable instrument.

\section{Methodology}

Based on theoretical models of transport choice and consumption theory in relation to sustainable consumption, a theory for influencing sustainable mobility behaviour will be developed.

For this purpose, general models of the transport mode choice like the one of Pez, the Theory of Planned Behaviour of Ajzen, the rational-choice-theory, the norm activation model and a consumption theory will be analysed. In addition, the deficit of environmental awareness and environmentally conscious action will be discussed. The aim is to explain why road users rarely opt for more sustainable means of transport despite a basic awareness of sustainability and the environment.

An approach to possible behavioural suggestion is worked out. Targeted suggestion is intended to encourage road users to transfer environmental awareness into environmentally conscious action.

By opting for sustainable means of transport, the traffic emissions of the road user can be reduced.

\section{Findings/Results}

First of all, there are different models that try to explain the decision for a particular means of transport.

At this point, a brief look will be taken at the following models and theories:

- In a nutshell: Aggregated, Behavioural and Attitudinal Models

- Choosing a means of transport as a purchase decision

- Choice of means of transport according to Pez and in comparison to choices under high and low involvement

- Transportation choice in the Theory of Planned Behaviour

- Choice of means of transport within the framework of the norm activation model 
- Transportation choice in the Rational-Choice-Theory

\section{In a Nutshell: Aggregated, Behavioural and Attitudinal Models}

Historically, 3 classical models for forecasting the choice of means of transport have been developed and evolved.

First, the choice of transport mode was determined using aggregated transport demand models. The choice of means of transport was derived depending on sociodemographic and settlement structural influencing factors. Individual behaviour is not taken into account.

The second generation of transport mode choice models was the disaggregated behavioural models. They also take into account objectively measurable properties of the means of transport and examine the electoral process on an individual level. It is assumed that a road user chooses the alternative with the greatest benefit. The properties travel costs and travel time were used for the decision.

Based on this, attitudinal models go one step further and also include subjective criteria. These include comfort, safety and convenience. It is assumed that there is a clear connection between a user's attitude to a means of transport and later behaviour.

\section{Important Findings for the Suggestion Instrument}

Based on these basic models, different models and theories are now used. What is decisive and remarkable, however, is that the attitudinal models already assume that attitudes to a means of transport influence the decision and behaviour (Research Information Centre 2018).

\section{Choosing a Means of Transport as a Purchase Decision}

For example, the choice of means of transport can be regarded as a classic purchase decision.

Based on models for the purchase decision, especially the structural models, as presented by Zemlin, it can be said that the decision for a means of transport, if it is a purchase decision, is influenced by psychological processes. Zemlin distinguishes between cognitive (rational) and emotive processes. In addition, external influences influence these mental processes, as shown in Figure 3 (Zemlin 2005). 
Figure 3. Differentiated Structural Model of Buyer Behaviour

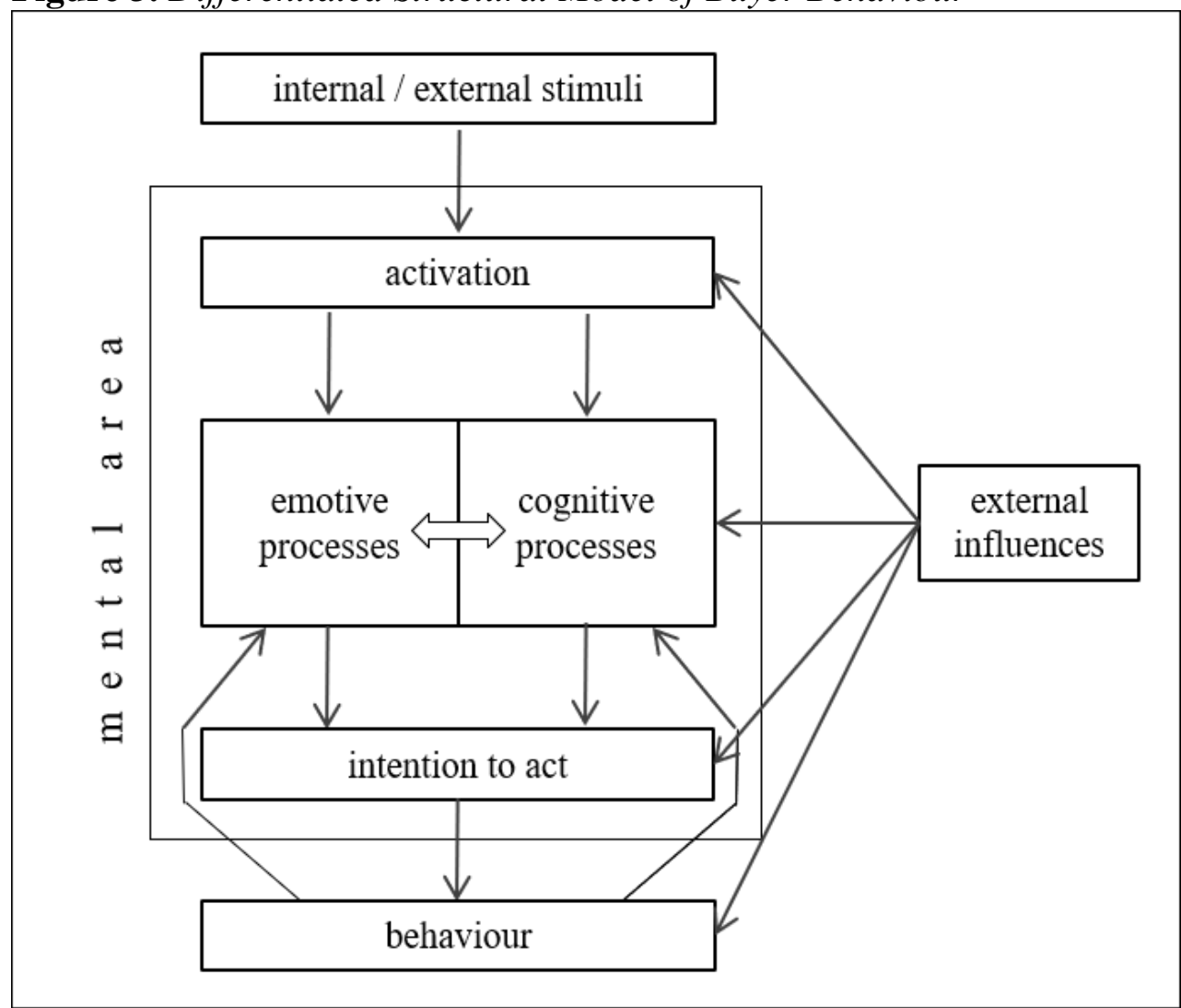

Source: Zemlin 2005.

This model makes it clear that the psychological process and the external environment are decisive; a first important insight for the development of a suggestion instrument.

\section{Important Findings for the Suggestion Instrument}

A transport choice decision can be interpreted as a purchase decision. Thus there are parallels. In purchasing behaviour, emotive and cognitive processes play a decisive role, as does the environment with external stimuli and external influences.

\section{Choice of Means of Transport according to Pez}

If we take a closer look at the model of Pez, which has already been presented, we can describe a number of conspicuous features. Sometimes there are parallels to the purchase decision theory mentioned above.

First of all, Pez represents a branching in the decision tree, which in other places in the literature are described comparatively with high and low involvement as well as habitual decisions. First of all, it is crucial whether the road user will make a decision at all. Zemlin describes this by saying that the decrease in involvement also leads to a reduction in the scope of mental processes when 
involvement describes the mental commitment to decision making. The less this is noticeable, the less complex the decision-making process becomes, up to and including habitual behaviour, in which de facto no decision-making process takes place anymore.

In the decision-making process, these two extremes (high involvement extensive decision-making process) and habitualised behaviour (no decisionmaking process) are represented by a fork in the decision tree. Pez says that a detailed decision can only be made if more than one alternative is perceived. In this case psychological processes follow to compare and evaluate the perceived alternatives. These are influenced by the environment. It is only at the end of these processes that the choice of means of transport is made. If only one alternative is perceived, the decision tree is shortened and psychological processes do not take place.

\section{Important Findings for the Suggestion Instrument}

On the one hand, it is important to recognize that a psychological process only takes place if the road user perceives alternative means of transport at all. This limits the potential situations to be influenced. On the other hand, Pez's model clearly shows that a psychological process is a central point in the choice of means of transport and how it takes place. Thus, Pez shows the process stages in which suggestion is possible, namely during the comparison and evaluation process.

\section{Transportation Choice in the Theory of Planned Behaviour}

Both the Theory of Planned Behaviour (Ajzen 1991) described here and the Norm-Activations-Model (Onwezen et al. 2013) have proven their worth empirically for the explanation of environmentally friendly behaviour, as well as in the field of choice of means of transport. "What both action models have in common is that they focus on individual internal evaluation processes when explaining environmentally relevant behaviour and not, like behavioural economic and activity-based models, exclusively on individual external requirements and constraints of mobility-related activities." (Hunecke 2015).

The Theory of Planned Behaviour assumes that psychological constructs, subjective norms, attitudes towards cars, public transport and bicycles, and perceived behavioural control influence behavioural intentions. Depending on how strongly the intention is pronounced and the extent of the perceived behavioural controls, the intention is transformed into behaviour. An intention is formed when the behaviour is evaluated positively (attitudes), other persons expect the behaviour (subjective norm) and the behaviour is easy to carry out (perceived behaviour control).

The focus of the Theory of Planned Behaviour is therefore on subjective advantages as motivation for behavioural execution. 
Choice of Means of Transport within the Framework of the Norm Activation Model

The norm activation model has a different focus than the Theory of Planned Behaviour. It regards the assumption of personal responsibility for fellow human beings and for the environment as an essential motivation for one's own compliance.

At the centre of the norm activity model is the personal norm, also known as the responsibility norm. If this personal norm is activated, this leads to a feeling of moral obligation, which in turn entails corresponding ecologically responsible behaviour.

In order to achieve this ecologically responsibility, it is essential that road users see themselves as co-responsible for environmental impacts and recognize the link between their actions and the environmental consequences.

\section{Important Findings for the Suggestion Instrument}

A decisive finding of the Theory of Planned Behaviour and the norm activation model are two assumed motivations for behavioural executions: on the one hand personal subjective advantages (Theory of Planned Behaviour) and on the other hand, the assumption of responsibility for the environment and fellow human beings. For the suggestion instrument to be developed, both possible motivational bases should be taken up and, if possible, included.

Equally important is the fact that social responsibility only leads to environmentally conscious conduct if one has understood the connection between one's own actions and the ecological consequences.

\section{Transportation Choice in the Rational-Choice-Theory}

Economic explanatory models, based on disaggregated behaviour-oriented models, work with the rational choice approach. This is based on the assumption that an individual always chooses the alternative action that promises the greatest personal benefit. Accordingly, objective factors such as time and money dominate the choice of means of transport.

In situations where behavioural costs are low, the theory of benefit maximization cannot be applied, as attitudes and moral convictions gain in importance.

\section{Important Findings for the Suggestion Instrument}

According to the rational choice approach, the suggestion instrument should take into account that the user may choose the alternative with the greatest personal benefit. The suggestion instrument must therefore increase the benefit of the environmentally friendly option in terms of hard factors such as time and money compared to the other alternatives. 
Conclusions from the Above Models and Theories and the Gap between Environmental Awareness and Environmental Action

The fact that the environmental aspect plays only a minor role in the choice of means of transport is one of the key findings of this work. This fact raises the question of how environmentally sound transport choices can be made.

Similarly, a result of the analyses of theories and models is the determination already made above of the factors and decisive properties that are important for the suggestion instrument. All the important findings should be taken into account in the development of the suggestion instrument.

In order to approach the topic of environmentally conscious behaviour and consumption, it will first be explained why environmental awareness does not lead directly to environmentally friendly behaviour, how the ecological aspect can have an effect as a value, especially against the background of changing values, which approaches are known to promote environmentally friendly presence and which role the aspect of environmental compatibility plays in the choice of means of transport.

\section{On the Discrepancy between Consciousness and Action}

It is not always easy for consumers to correctly assess the sustainability properties of products (Schoenheit 2009). Since the decision to use a means of transport is also a consumer behaviour, parallels can be drawn.

"The sustainability properties of products, which in principle range from manufacture to use to disposal, are "not written on the forehead" of the products. As a rule, these are so-called trust properties, which are not really judged by consumers either before or after the purchase, but can essentially only be "believed". Separate and particularly "credible" information offerings are therefore required in order to make the sustainable qualities of products and services visible and recognizable." (Schoenheit 2009).

This raises a crucial question: How can road users be provided with credible information about the sustainability quality of their intended means of transport?

The decision as to which means of transport should be chosen for a necessary change of location is a classic consumer decision. The consumer chooses between different products (the means of transport) the one that seems most optimal for a particular situation. This decision can be explained in more detail using the decision theory. According to this theory, a trader (in this case the road user) would subjectively rationally decide on the best possible course of action by weighing the consequences of action (from the point of view of the trader) (Dierkes et al. 1988). However, it is sometimes not easy to understand based on which influences and within the framework of which psychological processes a road user decides on this or that means of transport. This purchasing decision process (the choice of means of transport) is a complex process. Models can help to describe and explain. Different models try to approach the decision-making process. The next chapter presents all current known models and theories. The same applies to the various influences on the choice of means of transport. First, 
however, the connection between environmental awareness and environmentally friendly action will be established in a more specific way and it will be explained how environmental awareness as a value has increased in importance and what this means for a sustainable choice of means of transport.

It remains questionable whether environmental awareness is already important in the area of mobility consumption. This statement should be questioned: "More and more consumers are interested in [...] the $\mathrm{CO}_{2}$ emissions of their cars". (Heidbrink and Schmidt 2009).

This statement clearly contradicts the data of the previous chapters. The specific emissions of passenger cars have hardly decreased in the past 25 years. There is therefore a discrepancy between the statement that consumers are more interested in the $\mathrm{CO}_{2}$ emissions of their car and reality. Heidbrink and Schmidt offer an approximation to explain this discrepancy: "A closer look shows, however, that the willingness to consume responsibly is not consistently implemented. Despite buying climate-friendly or fair-trade products, the majority continue to use the car for journeys to work and the plane for long-distance journeys. [...] So there is still a gap between awareness and action." (Heidbrink and Schmidt 2009).

However, this discrepancy does not only seem to exist in the area of mobility, but is also generally valid. Kuckartz and Rheingans-Heintze are of the opinion that the discrepancy between environmental awareness and environmental action depends on the field of action. Thus, you conclude that in the food sector there is still the greatest correlation, whereas in the energy and transport sectors it is much smaller (Kuckartz and Rheingans-Heintze 2006). Prose also describes the fact that although environmental awareness seems to be pronounced in large parts of the population, there does not seem to be a direct connection between people's awareness and behaviour. "The relatively high level of environmental awareness is therefore only inadequately expressed in corresponding energy-relevant (purchasing) decisions and behaviour patterns of the actors". (Prose 1994).

Blake has discovered three barriers that can prevent environmental awareness from leading to environmentally friendly behaviour.

These are individual barriers such as laziness or lack of interest, barriers of responsibility such as lack of efficiency, no need, lack of trust or ownership and barriers of practicality such as lack of time, lack of money, lack of information and the like.

This also partly confirms what has already been mentioned above. Missing information can prevent environmentally friendly behaviour from developing.

However, there are other barriers. These should be tried to overcome when considering how to get people to choose sustainable means of mobility (Blake 1999).

\section{Importance in the Context of Transport Mode Choice Suggestion}

The previous findings are important for the development of a suggestion instrument. Sometimes it is possible that the environmental aspect is important for a road user, but it cannot be decisive for the behaviour or the choice of means of 
transport, as there is a discrepancy between awareness and behaviour. So the challenge is as follows: how can the suggestion instrument resolve the discrepancy?

Prose believes that one way can be marketing for climate protection and describes it as a strategy of behavioural change. "It is about both reducing environmentally harmful conduction (de-marketing) and strengthening relatively more environmentally friendly behaviour alternatives (marketing). Marketing as a strategy for changing habits requires knowledge of its object, i.e. behaviour and its determinants". (Prose 1994).

Furthermore, the suggestion instrument is more or less a marketing tool, which, following Prose, promotes environmentally harmful means of transport in a negative way (de-marketing) and promotes more environmentally friendly means of transport in a positive way (marketing).

The widespread use of smartphones supports and promotes mobile marketing. Apps are promising marketing instruments. "Apps can be used to address customers on a very intimate, emotional level, as users build a very special personal relationship with their device by constantly keeping their smartphones with them (Tosic 2015).

Therefore, a suggestion instrument in the form of a digital app that is used for marketing and de-marketing of means of transport is considered promising. Marketing should support environment-friendly modes of transport and on the other hand, non-friendly modes could be less attractive caused by de-marketing. A change of mobility decisions is expected.

Based on the theory and model analysis, the suggestion instrument should support the following principles:

It starts with the psychological emotive and cognitive processes in the choice of means of transport. It takes into account that suggestion is only possible if several alternative choices are made. In the absence of perception, for example due to fixed routines, a suggestion is not possible that the psychological decisionmaking process is not triggered in the first place. Suggestion takes place optimally at the moment of evaluation and comparison of the alternatives with regard to hard and soft factors.

The suggestion instrument offers personal advantages so that the individual chooses the environmentally friendly option. The suggestion instrument appeals to the sense of responsibility for the environment and fellow human beings. In addition, the suggestion instrument for environmentally friendly options maximizes personal benefit.

Based on the Previous Findings: What are Important and Useful Elements of the Suggestion Instrument?

The suggestion instrument starts with the psychological process of the decision.

It can work with a bonus system that offers personal benefits and at the same time increases the use of environmentally friendly means of transport.

At this point, the possibility of gamification features is in discussion. These features help to realize personal advantages and maximize benefits, as well as to 
build responsibility for the environment and fellow human beings. Gamification makes it easy to give users an understanding of the relationship between their own behaviour and environmental impacts. Gamification features can be a further step of influencing choice of mode of transport, assuming that gamification features can increase the use and the impact of a suggestion instrument. Different modes of gamification are possible.

Teresa Engel has investigated whether gamification can lead to an intended change in behaviour in the choice of means of transport (Engel 2017). Based on her work, it can be concluded that this is possible if the appropriate gamification elements are selected. With the help of these elements, based on the motivation theory, gamification can support the suggestion instrument in the achievement of its objectives. The corresponding features are therefore included in the planning and development of the suggestion instrument.

\section{Conclusions}

It is considered possible for a suggestion instrument to bring about a desired and targeted change in behaviour.

For successful suggestion, the instrument an optimally integration for the specific application is needed.

The following parameters are important when designing the suggestion instrument:

- Simple and unobtrusively use of the instrument

- Influence, without the user consciously or disruptively perceiving it

- Influence by means of simple and intuitive picture language

- Transparent and credible information

- Personal benefits occur

- Compensation for potential disadvantages of environmentally friendly means of transport (maximisation of personal benefit)

- Building a personal connection to the instrument and its contents

- Integration with common systems and processes to increase acceptance and utilization

- Concentration on a target group that is susceptible to influence through marketing or de-marketing

- Orientation and design of the suggestion depending on the target group and the environment

- Gamification as the key to motivation

- Building a sense of responsibility for the environment and fellow human beings

This paper covers basic research. This was necessary for the development of the suggestion app. It provides insights into theoretical models and theories that determine the functionality of a suggestion instrument. 
This basic research is therefore important in order to develop a corresponding instrument that takes these models and theories and the principles and modes of action derived from them into account.

Building on the knowledge gained and the parameters worked out, the suggestion instrument can be designed in the next step.

The goal of the research, consisting of the existing basic research and the following application research, divided into development and testing of the instrument, is the goal-oriented, voluntary change of behaviour in traffic behaviour, caused by so-called soft policies, implemented as an app.

The proposal for the suggestion instrument is therefore as follows:

An app that uses a comparison of emission data from different means of transport to make information available to users in a pictorial and easily understandable form. With the help of visual language, gamification and credible data, the user builds up a sense of responsibility, gains an understanding of the environmental impact of his own behaviour and receives incentives to adapt his behaviour to the desired objectives.

The development of the app is a central element of the following application research. The basic research in this paper has shown that a suggestion instrument is suitable for changing mobility behaviour.

Figure 4 and 5 show the original way of decision making for one mode of transport and the principle for the created instrument to support a sustainable decision making.

Figure 4. Original Way of Decision Making for One Mode of Transport

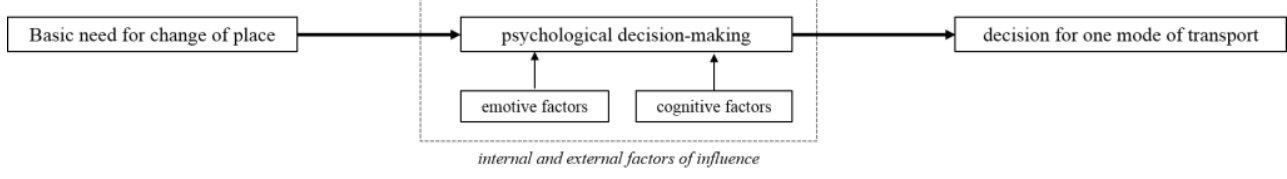

Figure 5. Created Instruments to Support a Sustainable Decision Making

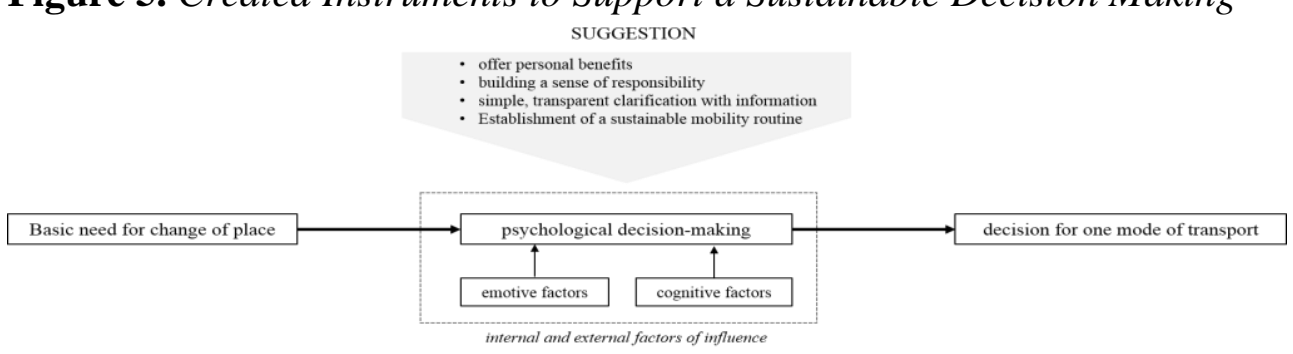

With help of the created instrument to support a sustainable decision making, the way of decision making is more complex. The suggestion influences at the stage of psychological decision making. Besides emotive and cognitive factors, the suggestion factors will influence the process. The key influencing factors are the offer of personal benefits, a building of a sense of responsibility, simple and transparent clarification with information and the establishment of a sustainable mobility routine, as it was derived in this paper. 
The developed model of suggestion will be realized in an app and evaluated in a field study.

\section{References}

Ajzen I (1991) The Theory of Planned Behaviour. Organizational Behaviour and Human Decision Processes 50(2): 179-211. DOI=10.1016/0749-5978(91)90020-T.

Blake J (1999) Overcoming the 'Value-Action Gap' in Environmental Policy: Tensions between National Policy and Local Experience. Local Environment 4(3). DOI $=10.1080 / 13549839908725599$.

Busch-Geertsema A (2018) Mobilität von Studierenden im Übergang ins Berufsleben. [Mobility of Students in Transition to Working Life]. Die Änderung mobilitätsrelevanter Einstellungen und der Verkehrsmittelnutzung. DOI=http://dx.doi.org/ 10.1007/978-3-658-18686-9.

Deutsch V (2013) Mobil Bleiben in der Fläche: Für einen Integrierten ÖPNV. [Staying Mobile in Space: For an Integrated Public Transport System]. Köln: Verband Deutscher Verkehrsunternehmen e.V.

Dierkes M, Fietkau HJ (1988) Umweltbewußtsein, Umweltverhalten. [Environmental Awareness, Environmental Behaviour]. Kohlhammer, Stuttgart: Metzler-Poeschel.

Engel T (2017) Beeinflussung der Verkehrsmittelwahl durch Gamification [Influencing the Choice of Means of Transport through Gamification]. ATZ Automobiltechnische Zeitschrift.

Federal Republic of Germany (1949) Basic Law for the Federal Republic of Germany.

Forschungsinformationszentrum - Research Information Centre (2018) Prognosen zur Verkehrsmittelwahl (Modal Split) [Forecasts on the Choice of Transport Mode (Modal Split)].

Fuji S, Gärling T (2003) Development of Script-Based Travel Mode Choice after Forced Change. Transportation Research Part F Traffic Psychology and Behaviour 6(2):117-124.

Fürst E, Oberhofer P (2012) Trends in der Mobilitätseinstellung von Studierenden und Mitarbeitern Deutschsprachiger Hochschulen. [Trends in the Mobility Attitudes of Students and Staff at German-Speaking Universities and Colleges]. In H Proff, J Schönharting, D Schramm, J Ziegler (eds), Zukünftige Entwicklungen in der Mobilität, 455-465.

Groß T (1998) Mobilitätsverhalten von Jugendlichen. Empirische Untersuchung zur Verkehrsmittelwahl und ihrer Determinanten als Beitrag zur an den ÖPNV in Dortmund. [Mobility Behaviour of Young People. Empirical Study on the Choice of Means of Transport and its Determinants as a Contribution to Public Transport in Dortmund]. Dortmund: Diplomarbeiten Agentur diplom.de.

Heckmann R, Mentzel B, Gaspers L (2019) HFTmobil: Untersuchung des Mobilitätsverhaltens von HFT-Angehörigen. [HFTmobil: Investigation of the Mobility Behaviour of HFT Members]. Stuttgart: Hochschule für Technik Stuttgart.

Heidbrink L, Schmidt I (2009) Die Neue Veranwortung der Konsumenten. [The New Responsibility of Consumers]. Aus Politik und Zeitgeschehen, 27-32.

Held M (1982) Verkehrsmittelwahl der Verbraucher. Beitrag einer Kognitiven Motivationstheorie zur Erklärung der Nutzung Alternativer Verkehrsmittel. [Choice of Means of Transport by Consumers. Contribution of a Cognitive Motivation Theory to the Explanation of the Use of Alternative Means of Transport].

Duncker \& Humblot; Auflage: 1. 
Hollerbach A, Berner U (2003) Klimawandel und $\mathrm{CO}_{2}$ aus Geowissenschaftlicher Sicht. [Climate Change and $\mathrm{CO}_{2}$ from a Geoscientific Point of View]. Presented at the Conference: Tagung Braunkohleverstromung 2003 der VDI-Gesellschaft Energietechnik. Koeln, Germany.

Hunecke M (2015) Mobilitätsverhalten Verstehen und Verändern. [Understanding and Changing Mobility Behaviour]. Wiesbaden: VS Verlag für Sozialwissenschaften. DOI=10.1007/978-3-658-08825-5.

Institut für angewandte Sozialwissenschaft GmbH - Institute for Social Science (2017) Mobilität in Deutschland. [Mobility in Germany].

IPCC (2014) Climate Change 2014: Mitigation of Climate Change. Cambridge and New York.

Kraftfahrt-Bundesamt - Federal Motor Transport Authority (2017) Downsizing. Nicht in jedem Segment ein Thema. [Downsizing. Not an Issue in Every Segment].

Kuckartz U, Rheingans-Heintze A (2006) Trends im Umweltbewusstsein Umweltgerechtigkeit, Lebensqualität und persönliches Engagement. [Trends in Environmental Awareness. Environmental Justice, Quality of Life and Personal Commitment]. Wiesbaden: VS Verlag für Sozialwissenschaften.

Onwezen M, Antonides G, Bartels J (2013) The Norm Activation Model: An Exploration of the Functions of Anticipated Pride and Guilt in Pro-Environmental Behaviour. Journal of Economic Psychology 39(Aug): 141-153.

Pez P (1998) Verkehrsmittelwahl im Stadtbereich und ihre Beeinflußbarkeit. Eine Verkehrsgeographische Analyse am Beispiel von Kiel und Lüneburg. [Choice of Transport Mode in Urban Areas and its Influence. A Traffic-Geographical Analysis using Kiel and Lüneburg as Examples]. Kiel: Geographisches Institut der Universität Kiel.

Prose F (1994) Ansätze zur Veränderung vom Umweltbewusstsein und Umweltverhalten aus Sozialpsychologischer Perspektive. [Approaches to Changing Environmental Awareness and Behaviour from a Socio-Psychological Perspective]. Senatsverwaltung für Stadtentwicklung und Umweltschutz Berlin (Hrsg.). Neue Wege im EnergiesparMarketing, Materialien zur Energiepolitik in Berlin Heft 16, 14-23.

Rheinisch-Westfälisches Institut für Wirtschaftsforschung (2010) Verkehrsinfrastrukturinvestitionen - Wachstumsaspekte im Rahmen einer Gestaltenden Finanzpolitik [Transport Infrastructure Investments - Growth Aspects within the Framework of a Shaping Financial Policy].

Rudinger G, Donaghy K, Poppelreuter S (2006) Societal Trends, Mobility Behaviour and Sustainable Transport in Europe and North America. European Journal of Ageing 1(1): 95-101.

Schoenheit I (2009) Nachhaltiger Konsum. [Sustainable Consumption]. Aus Politik und Zeitgeschehen, 19-26.

Tosic M (2015) Apps für KMU. Praktisches Hintergrundwissen für Unternehmer. [Apps for SMEs. Practical Background Knowledge for Entrepreneurs]. Wiesbaden: Gabler Verlag.

Zemlin B (2005) Das Entscheidungsverhalten bei der Verkehrsmittelwahl. [Decision Behaviour in the Choice of Means of Transport]. Wuppertal: Josef Eul Verlag; Auflage: 1. 